\title{
Influência da substituição parcial do feno de Coastcross pela casca de soja sobre a ingestão de alguns componentes nutricionais de dietas contendo diferentes fontes de nitrogênio, em bovinos ${ }^{1}$
}

\section{Influence at the partial substitution partial of Coastcross hay on the ingestion of some nutritional component in diets containing different sources of nitrogen, in steers}

\author{
Leandro das Dores Ferreira da Silva ${ }^{2 *}$; Jane Maria Bertocco Ezequiel ${ }^{3}$; \\ Paulo Sérgio de Azevedo ${ }^{6}$;osé Wanderley Cattelan ${ }^{4}$; José Carlos Barbosa ${ }^{5}$; \\ Ana Rosália Mendes ${ }^{7}$; Edson Luis de Azambuja Ribeiro ${ }^{8}$; \\ Marco Antônio da Rocha ${ }^{8}$; Valdecir de Souza Castro9.
}

\section{Resumo}

\begin{abstract}
Este experimento foi realizado para avaliar o efeito de dois níveis de casca de soja (CS) e de três fontes de nitrogênio sobre a ingestão de matéria seca (MS), matéria orgânica $(\mathrm{MO})$, proteína bruta $(\mathrm{PB})$, fibra em detergente neutro (FDN), fibra em detergente ácido (FDA), carboidratos não fibrosos (CNF) e de proteína insolúvel em detergente ácido (PIDA), em bovinos. Foram usados seis novilhos Holandês x Zebu com idade média de 12 meses e pesando em média $229 \mathrm{~kg}$ de peso, fistulados no rúmen. Os animais foram distribuídos em seis tratamentos em quadrado latino $6 \times 6$, alimentados individualmente de tal forma que ocorresse sobra de $10 \%$ da matéria seca fornecida. As fontes de nitrogênio não influenciaram a ingestão de MS, MO, PB, FDN e de FDA. Porém, foram observadas maiores ingestões de CNF quando os animais foram alimentados com amiréia do que quando receberam farinha de subprodutos de abatedouro avícola. Concluímos que a casca de soja pode substituir parcialmente a fração volumosa da ração de bovinos e a amiréia pode substituir totalmente o farelo de soja sem prejuízos na ingestão dos componentes nutricionais estudados.

Palavras -chave: Amiréia, volumoso, farelo de soja, fibra em detergente neutro, proteína bruta, subproduto avícola
\end{abstract}

1 Parte da Tese de Doutoramento (UNESP/Jaboticabal) do primeiro autor; Projeto financiado pelo CNPq.

2 Docente do Departamento de Zootecnia - UEL. UEL/CCA/DZOOT, Caixa Postal 6001, CEP 86051- 970, Londrina -PR. E-mail: leandro@uel.br.

3 Docente do Departamento de Zootecnia - UNESP - Jaboticabal/SP

${ }^{4}$ Docente do Departamento de Medicina Veterinária - UNESP - Jaboticabal/SP

Docente do Departamento de Matemática - UNESP - Jaboticabal/SP

Bolsista Pesquisador do departamento de Zootecnia - Universidade Federal da Paraíba

Docente do Departamento de Ciências Fisiológicas - UEL. UEL/CCB/DCF - Londrina/PR

8 Docentes do Departamento de Zootecnia - UEL . UEL/CCA/DZOOT - Londrina/PR

9 Aluno de Curso de Zootecnia, Bolsista PIBIC/CNPq /CCA. Universidade Estadual de Londrina, PR

* Autor para correspondência 


\begin{abstract}
This experiment was conducted in order to evaluate the effect of two levels of soybean hulls (SH) and three sources of nitrogen on the ingestion of dry matter (DM), organic matter $(\mathrm{OM})$, crude protein $(\mathrm{CP})$, neutral detergent fiber (NDF), acid detergent fiber (ADF), non fiber carbohydrates (NFC) and acid detergent insoluble protein (ADIP), in steers. Six Holstein x Zebu steers, with 12 months of age and 229 $\mathrm{kg}$ of live weight, rumen fistulated, were used. The animals were distributed in six treatments in a 6 × 6 Latin square design. They were individually fed allowing $10 \%$ DM leftover. The nitrogen sources did not influence the ingestion of DM, OM, CP, NDF and ADF. However, it was observed greater ingestion of NFC when animals were fed with starea than when they received "avian slaughter byproducts flour". It was concluded that the soybean hulls can partially substitute the roughage fraction of bovine ration, and that the starea can totally substitute the soybean meal without detriment in the ingestion of the studied nutritional components.
\end{abstract}

Key words: Starea, voluminous, soybean meal, neutral detergent fiber, crude protein, poultry by-products

\section{Introdução}

A ingestão voluntária de matéria seca pode ser definida como a quantidade máxima de matéria seca que um animal pode ingerir quando submetido a um manejo alimentar ad libitum. No entanto, algumas características tanto físicas como químicas podem ter efeitos positivos ou negativos sobre a ingestão total de matéria seca pelo animal. Estas características podem ser relacionadas à densidade energética, qualidade, quantidade e granulometria da fibra, podendo aumentar ou reduzir o tempo de permanência do alimento no rúmen, com reflexo positivo ou negativo sobre o consumo pela alteração no ritmo de passagem do conteúdo do rúmen-retículo para os outros compartimentos do trato digestivo.

O consumo de matéria seca é um dos fatores que mais influencia a performance produtiva do animal, sendo este influenciado por vários fatores como o próprio animal, alimento e principalmente, as condições de alimentação. A quantificação do consumo de alimentos em bovinos de corte é de suma importância para predição do ganho de peso, assim como, para o estabelecimento das exigências nutricionais necessários à formulação das dietas e fundamental para a nutrição, por determinar o nível de nutrientes ingeridos e, consequentemente, a resposta animal (NRC, 1996; VAN SOEST, 1994).

O consumo de matéria seca pelos ruminantes é dependente de fatores inerentes ao animal, ao alimento e ao meio, do peso vivo, nível de produção, variação no peso vivo, estádio de lactação, estado fisiológico, efetividade da fibra, volume, capacidade de enchimento, densidade energética, necessidade de mastigação, disponibilidade de alimento, espaço no cocho, tempo de acesso, freqüência de alimentação e das condições climáticas (MERTENS, 1992).

O consumo e a digestibilidade de nutrientes podem estar correlacionados entre si, dependendo da qualidade da ração. Para rações com alta digestibilidade e com baixo teor de fibra em detergente neutro (FDN), o consumo será menor devido a fatores quimiostáticos que controlam a ingestão pelo teor de energia e em rações com baixa qualidade e alto teor de FDN, o consumo será controlado pelo efeito enchimento (VAN SOEST, 1994; MERTENS, 1994).

A quantidade de FDN na dieta não está bem definida e pode variar em função do nível de produção animal e do tipo de forragem usada ou mais precisamente pela qualidade dessa fibra na dieta. $\mathrm{O}$ desejável é que o teor de FDN da ração exceda $25 \%$ da matéria seca (MERTENS, 1992), e que 70 a $75 \%$ dessa FDN seja provenientes de volumosos e não de fibras presentes nos grãos de cereais, para manter as condições ideais dentro do rúmen e não prejudicar a digestibilidade.

A concentração e a qualidade da proteína na dieta podem ter influências positivas ou negativas sobre o consumo por induzir alterações no mecanismo físico e/ou fisiológico. Segundo Roseler, Ferguson e Sniffen 
(1993) quando o teor de proteína bruta da dieta estiver abaixo de $12 \%$, ou se ocorrer indisponibilidade de nitrogênio, ocorrerá reduções na digestão da fibra e consequentemente, haverá restrições no consumo. Por outro lado, níveis elevados de nitrogênio-não-protéico podem induzir à toxidez de microrganismos pelo excesso de liberação de amônia, reduzindo desta forma, o consumo total de matéria seca da dieta (NRC, 1996).

Em rações com baixas disponibilidades de compostos nitrogenados, e ricas em FDN o suprimento de proteína degradável no rúmen (PDR) pode tornar-se fator limitante para o crescimento microbiano, o que leva ao comprometimento da digestão da parede celular e na ingestão de alimentos.

Van Soest (1994), comenta que com dietas de baixa qualidade, vários fatores podem estar relacionados ao controle do consumo, como limitações no tempo de alimentação, enchimento e conseqüente limite da distensão ruminal, ou até mesmo, deficiências de nitrogênio, elevadas produções de ácido acético em dietas ricas em fibra e carência de outro nutriente que possa estar envolvido no mecanismo.

O objetivo deste estudo foi determinar o consumo ad libitum de matéria seca (MS), matéria orgânica (MO), FDN e de fibra em detergente ácido (FDA) de bovinos alimentados com rações completas com 40 e $60 \%$ de concentrado e volumoso, contendo milho, amiréia, farelo de soja, subproduto de abatedouro avícola e 30 ou $70 \%$ de casca de soja em substituições ao feno de capim Coastcross.

\section{Material e Métodos}

Este experimento foi conduzido nas dependências do Departamento de Zootecnia da Faculdade de Ciências Agrárias e Veterinárias - FCAV/UNESP, no município de Jaboticabal, SP. Foram usados seis novilhos mestiços (Holandês x Zebu), castrados, com 12 meses de idade, pesando em média de $230,00 \mathrm{~kg}$, canulados no rúmen e no abomaso, distribuídos em modelo de quadrado latino com 6 (seis) tratamentos.
Antes de iniciar a fase experimental e a cada 42 dias os novilhos foram vermifugados e submetidos a um período de adaptação às condições de confinamento, em baias individuais com piso de concreto, portando cochos e bebedouros. Os animais foram pesados ao término de cada período experimental para ajuste de consumo de matéria seca (MS).

Os alimentos usados nas formulações das rações experimentais foram feno de capim Coastcross (FCC), casca do grão de soja (CS), considerado volumoso e farelo de soja (FS), amiréia 72\% (AM), farinha de subprodutos de abatedouro avícola (FSAA), como fontes protéicas, e o grão de milho moído (GMM) como fonte energética.

As rações foram formuladas de forma que contivessem $75 \%$ de nutrientes digestíveis totais (NDT) e $13 \%$ de proteína bruta (PB), sendo o sal mineralizado (SM) misturado na ração concentrada a $0,7 \%$, base na $\mathrm{MS}$.

Os animais receberam ad libitum, rações em duas porções às 8:00 (oito) e às 18:00 horas, de forma que houvesse sobras de 5 a 10\% da MS fornecida, diariamente. O consumo de ração pelos animais foi determinado durante seis períodos de 30 dias, sendo 15 de adaptação, 14 de coletas de amostras das rações e das sobras e 1 (um) dia de descanso a pasto de Coastcross. A ingestão diária de matéria seca e de seus componentes nutritivos foi obtida pela diferença entre o fornecido e a sobra.

Cada animal, dentro de período, recebeu um dos tratamentos T1, T3 e T5 composto com $60 \%$ de mistura volumosa $(70 \%$ de FCC $+30 \%$ CS) e $40 \%$ de concentrado com milho, sal mineralizado e uma das fontes de proteína respectivamente, FS, FSAA e AM e T2, T4 e T6 compostos com 60\% de mistura volumosa $(30 \%$ de FCC $+70 \%$ de $\mathrm{CS})$ e $40 \%$ de concentrado com milho, sal mineralizado e uma das fontes de proteína anteriormente citadas. A composição química e bromatológica dos ingredientes usados, proporções de feno e de cascas de soja das rações usados neste estudo podem ser visualizadas nas Tabelas 1 e 2, respectivamente. 
Silva, L. D. F. da et al.

Tabela 1. Composição química dos ingredientes usados nas rações ${ }^{1}(\% \mathrm{MS})$

\begin{tabular}{lrccccc}
\hline $\begin{array}{l}\text { Ingredientes } \\
\text { Nutrientes }\end{array}$ & Feno & Casca de soja & Milho moído & Farelo de soja & Amiréia & $\begin{array}{c}\text { Far. sub. abat. } \\
\text { avícola }\end{array}$ \\
\hline MS & & & & & & \\
PB & 89,99 & 89,99 & 87,70 & 88,19 & 88,73 & 94,17 \\
MO & 4,82 & 11,95 & 10,01 & 49,87 & 77,01 & 52,15 \\
FDN & 95,50 & 94,75 & 98,54 & 93,02 & 95,99 & 88,87 \\
FDA & 89,56 & 77,24 & 9,40 & 26,57 & 27,47 & \\
LDA $^{2}$ & 47,23 & 52,64 & 6,72 & 13,02 & 8,16 & \\
Hemicelulose & 7,55 & 1,39 & 0,25 & 0,55 & 0,24 & \\
Celulose $_{\text {Lignina }}^{3}$ & 42,33 & 24,60 & 2,68 & 13,37 & 19,31 & \\
\hline
\end{tabular}

${ }^{1}$ Dados obtidos no LANA (Laboratório de Nutrição Animal, FCAV/UNESP, Jaboticabal - SP).

${ }^{2}$ LDA : Lignina em digestão ácida (H2SO4 a 72\%).

${ }^{3}$ Lignina : Obtida através de oxidação com Permanganato de Potássio.

As quantidades de MS, MO, PB, FDN, FDA, composição da ingestão média de cada um dos carboidratos não fibrosos (CNF), proteína insolúveis componentes nutritivos por animal e por período em detergente ácido (PIDA) e de lignina ingeridas experimental conforme (SILVA; LEÃO, 1979). diariamente, foram determinadas a partir da

Tabela 2. Porcentagem dos ingredientes e composição bromatológica das rações experimentais (\% MS $)^{1}$

\begin{tabular}{|c|c|c|c|c|c|c|}
\hline & \multicolumn{6}{|c|}{ Rações Experimentais } \\
\hline & 1 & 2 & 3 & 4 & 5 & 6 \\
\hline \multirow[t]{2}{*}{ Ingredientes } & (FCC:CS) & (FCC:CS) & (FCC:CS) & (FCC:CS) & $(\mathrm{FCC}: \mathrm{CS})$ & (FCC:CS) \\
\hline & $70: 30$ & $30: 70$ & $70: 30$ & $30: 70$ & $70: 30$ & $30: 70$ \\
\hline $\mathrm{FCC}^{*}$ & 42,0 & 18,0 & 42,0 & 18,0 & 42,0 & 18,0 \\
\hline $\mathrm{CS}^{*}$ & 18,0 & 42,0 & 18,0 & 42,0 & 18,0 & 42,0 \\
\hline GMM $^{*}$ & 26,1 & 30,2 & 27,8 & 31,3 & 31,2 & 33,7 \\
\hline $\mathrm{FS}^{*}$ & 13,2 & 9,1 & & & & \\
\hline FSAA $^{*}$ & & & 11,5 & 8,0 & & \\
\hline $\mathrm{AM}^{*}$ & & & & & 8,1 & 5,6 \\
\hline Sal mineral & 0,7 & 0,7 & 0,7 & 0,7 & 0,7 & 0,7 \\
\hline \multicolumn{7}{|c|}{ Composição química e bromatológica ${ }^{1}$} \\
\hline $\mathrm{MO}$ & 95,35 & 95,60 & 92,05 & 91,79 & 95,07 & 95,78 \\
\hline PB & 13,60 & 13,70 & 13,20 & 12,90 & 12,90 & 13,90 \\
\hline FDN & 61,75 & 59,92 & 61,54 & 60,17 & 61,67 & 57,58 \\
\hline FDA & 31,65 & 33,25 & 31,38 & 32,44 & 31,34 & 32,59 \\
\hline EE & 1,20 & 1,61 & 3,17 & 3,52 & 1,99 & 2,37 \\
\hline $\mathrm{CNF}^{2}$ & 21,10 & 22,77 & 15,77 & 16,38 & 19,89 & 23,21 \\
\hline PIDA $^{3}$ & 2,30 & 2,40 & 1,63 & 1,18 & 1,38 & 1,28 \\
\hline $\mathrm{LDA}^{5}$ & 3,53 & 2,06 & 4,26 & 3,00 & 3,56 & 2,07 \\
\hline Lignina $^{4}$ & 2,95 & 2,25 & 2,80 & 2,11 & 3,00 & 2,25 \\
\hline
\end{tabular}

${ }^{1}$ Dados obtidos através de análise no LANA (Laboratório de Nutrição Animal, FCAV/UNESP, Jaboticabal - SP)

${ }^{2} \mathrm{CNF}=\mathrm{MO}-[\mathrm{FDN}+\mathrm{EE}+(\mathrm{PB}-(\mathrm{NIDA} * 6,25))]$.

${ }^{3} \mathrm{PIDA}=($ Nitrogênio insolúvel em detergente ácido $) * 6,25$.

${ }^{5} \mathrm{LDA}=$ Lignina em digestão ácida. ${ }^{4}$ Lignina $=$ Obtida através de oxidação com Permanganato de Potássio. *Feno de coast-cross (FCC), Casca de soja (CS), Grão de milho moído (GMM), Farelo de soja (FS), Farinha de subproduto de abatedouro avícola (FSAA) e Amiréia (AM) 
Todas as amostras compostas foram trituradas em moinho dotado com peneira de crivos de $1 \mathrm{~mm}$ de diâmetro para posteriores análises em laboratório. Nas amostras do feno de capim Coastcross, da casca de soja, das rações concentradas e das sobras foram determinados os teores de matéria seca, matéria mineral, proteína bruta, fibra em detergente neutro, fibra em detergente ácido, nitrogênio insolúvel em detergente ácido e de lignina conforme metodologias citadas por Silva e Queiroz (2002), enquanto que os teores de lignina em digestão ácida, com $\mathrm{H}_{2} \mathrm{SO}_{4}$ segundo ASSOCIATION OF OFFICIAL ANALYTICAL CHEMSTS (1998) e os teores de CNF foram obtidos pela seguinte fórmula:

$\mathrm{CNE}(\%)=\mathrm{MO}-\left[\mathrm{FDN}+\mathrm{EE}+\left(\mathrm{PB}-\left(\mathrm{NIDA}^{*} 6,25\right)\right)\right]$
Todas as análises foram realizadas com o auxílio do programa estatístico SAS (SAS, 1990), sendo descritas pelo seguinte modelo estatístico:

$\mathrm{Y}_{\mathrm{ijkl}}=\mu+\mathrm{a}_{\mathrm{i}}+\mathrm{p}_{\mathrm{j}}+\mathrm{f}_{\mathrm{k}}+\mathrm{c}_{1}+\mathrm{fc}_{\mathrm{kl}}+\mathrm{e}_{\mathrm{ijkl}}$, e as diferenças entre médias detectadas pelo teste de Tukey.

\section{Resultados e Discussão}

As fontes protéicas não apresentaram efeitos significativos $(\mathrm{P}>0,01)$ sobre a ingestão de $\mathrm{MS}, \mathrm{MO}$, $\mathrm{PB}, \mathrm{FDN}$ e de FDA em quaisquer das unidades utilizadas para expressar o consumo. Estes resultados podem ser visualizados na Tabela 3.

Tabela 3. Efeito das fontes protéicas, amiréia (AM), farinha de subproduto de abatedouro avícola (FSAA) e farelo de soja (FS), sobre os consumos médios diários de matéria seca e de seus constituintes nutritivos estudados nas rações.

\begin{tabular}{|c|c|c|c|c|}
\hline & $\overline{\mathrm{AM}}$ & FSAA & FS & $\mathrm{CV}(\%)^{3}$ \\
\hline & \multicolumn{4}{|c|}{ Matéria seca (MS) } \\
\hline$\% \mathrm{PV}$ & 2,4 & 2,5 & 2,3 & 19,7 \\
\hline $\mathrm{kg} / \mathrm{d}$ & 7,1 & 7,1 & 6,9 & 15,0 \\
\hline \multirow[t]{2}{*}{$\mathrm{g} / \mathrm{kg}^{0,75}$} & 99,2 & 99,5 & 96,1 & 21,0 \\
\hline & \multicolumn{4}{|c|}{ Matéria orgânica (MO) } \\
\hline$\% \mathrm{P})$ & 2,3 & 2,4 & 2,2 & 19,6 \\
\hline $\mathrm{kg} / \mathrm{d}$ & 6,8 & 6,8 & 6,6 & 15,0 \\
\hline \multirow[t]{2}{*}{$\mathrm{g} / \mathrm{kg}^{0,75}$} & 95,1 & 94,7 & 91,8 & 21,0 \\
\hline & \multicolumn{4}{|c|}{ Proteína bruta $(\mathrm{PB})$} \\
\hline$g / d$ & 806,0 & 810,6 & 770,5 & 17,1 \\
\hline$\% \mathrm{PV}^{2}$ & 0,3 & 0,3 & 0,3 & 20,8 \\
\hline \multirow[t]{2}{*}{$\mathrm{g} / \mathrm{kg}^{0,75}$} & 11,3 & 11,4 & 10,7 & 22,9 \\
\hline & \multicolumn{4}{|c|}{ Fibra em detergente neutro (FDN) } \\
\hline $\mathrm{kg} / \mathrm{d}$ & 4,2 & 4,5 & 4,2 & 14,8 \\
\hline$\% \mathrm{PV}$ & 1,4 & 1,6 & 1,4 & 19,6 \\
\hline \multirow[t]{2}{*}{$\mathrm{g} / \mathrm{kg}^{0,75}$} & 58,4 & 62,8 & 58,1 & 20,9 \\
\hline & \multicolumn{4}{|c|}{ Fibra em detergente ácido (FDA) } \\
\hline $\mathrm{kg} / \mathrm{d}$ & 2,2 & 2,2 & 2,2 & 16,4 \\
\hline$\% \mathrm{PV}$ & 0,8 & 0,8 & 0,7 & 22,0 \\
\hline \multirow[t]{2}{*}{$\mathrm{g} / \mathrm{kg}^{0,75}$} & 31,3 & 31,2 & 30,7 & 22,8 \\
\hline & \multicolumn{4}{|c|}{ Proteína insolúvel em detergente ácido (PIDA) } \\
\hline$(\mathrm{g} / \mathrm{d}$ & $92,0 \mathrm{~b}$ & $95,2 b$ & $166,3 \mathrm{a}$ & 17,4 \\
\hline \multirow[t]{2}{*}{$\mathrm{g} / \mathrm{kg}^{0,75}$} & $1,3 \mathrm{~b}$ & $1,3 \mathrm{~b}$ & $2,3 \mathrm{a}$ & 22,8 \\
\hline & \multicolumn{4}{|c|}{ Carboidratos não fibrosos (CNF) } \\
\hline $\mathrm{kg} / \mathrm{d}$ & $1,6 \mathrm{a}$ & $1,2 \mathrm{~b}$ & $1,4 \mathrm{ab}$ & 15,8 \\
\hline$\% \mathrm{PV}$ & $0,6 \mathrm{a}$ & $0,4 \mathrm{~b}$ & $0,5 \mathrm{ab}$ & 20,9 \\
\hline $\mathrm{g} / \mathrm{kg}^{0,75}$ & $22,8 \mathrm{a}$ & $16,6 b$ & $20,3 \mathrm{ab}$ & 21,5 \\
\hline
\end{tabular}

"Médias acompanhadas de letras diferentes na mesma linha diferem estatisticamente pelo Teste Tukey $(\mathrm{P}<0,05)$.

${ }^{2}$ Peso vivo. ${ }^{3}$ Coeficiente de variação. 
Os animais alimentados com farelo de soja apresentaram maiores $(\mathrm{P}<0,05)$ consumos de proteína insolúvel em detergente ácido (PIDA) do que aqueles com amiréia e com farinha de subproduto de abatedouro avícola (FSSA), os quais apresentaram consumos de PIDA semelhantes entre si (Tabela 3). Pode-se verificar na Tabela 2 que as rações contendo farelo de soja apresentaram maiores teores de PIDA do que as demais fontes protéicas usadas neste estudo.

A introdução de amiréia nas rações conferiu maior consumo $(\mathrm{P}<0,05)$, nas três unidades de expressão de ingestão (Tabela 3), de carboidratos não fibrosos (CNF) do que a FSSA. No entanto, o consumo de CNF da ração com farelo de soja foi semelhante $(\mathrm{P}>0,05)$ às ingestões observadas com os animais alimentados com as rações contendo FSSA e com amiréia.

O maior consumo, expressos nas diferentes unidades, de CNF pode ser atribuído, em parte, à sua presença em maior quantidade nas rações com amiréia (Tabela 2), em relação às com farinha de subproduto de abatedouro avícola, já que o consumo de matéria seca, apresentado pelos animais, foi semelhante entre as rações (Tabelas 3). Neste sentido, pode-se afirmar que fatores como teor de FDN, densidade e de energia não apresentaram efeitos negativos na ingestão. O que segundo Forbes (1995), as dietas com baixas densidades, caracterizadas pelos elevados teores de fibra, têm influências negativas no consumo devido às particularidades do trato digestivo dos animais ruminantes, devido estas necessitarem de maiores tempos de permanência para fermentação, o que leva a reduções das quantidades de MO consumida e digerida. Por outro lado, o aumento da densidade da dieta através de concentrados pode acarretar em alterações na dinâmica ruminal, principalmente pela redução do $\mathrm{pH}$.
Observa-se na Tabela 4 que os consumos em g/ $\mathrm{kg}^{0,75}$ de MS, MO, PB, FDN, FDA e de PIDA, não diferiram entre níveis de casca de soja em substituição ao feno de capim Coastcross. Pode-se verificar, ainda, que a casca de soja influenciou $(\mathrm{P}<0,05)$ positivamente sobre o consumo de $\mathrm{CNF}$, em quaisquer das unidades usadas.

Os resultados observados no presente estudo tenderam a confirmar as afirmações de Macgregor, Owen e Mcgill (1976) de que o tamanho das partículas da casca de soja facilitaria a velocidade de passagem através do rúmen-retículo, o que permitiria maior ingestão de MS e, consequentemente, de outros componentes nutritivos. Estas observações podem ser certificadas na Tabela 4 , onde se observa que houve tendências para maiores consumos dos vários componentes nutritivos quando os animais receberam rações com níveis de $70 \%$ de casca de soja em substituição ao feno de capim Coastcross do que quando os animais foram alimentados com rações com 30\% de substituição do mesmo feno. Além disso, o consumo é inversamente relacionado ao teor FDN indigestível que ocupa espaço do trato digestível, reduzindo o consumo. Além da indigestibilidade, as taxas de digestão e de passagem da fibra pelo trato gastrointestinal são altas e positivamente correlacionadas com o consumo (MERTENS; ELY, 1979). Por outro lado, em muitas outras situações, o consumo é positivamente correlacionado a digestibilidade da dieta (WALDO; JORGENSEN, 1981). 
Tabela 4. Efeitos dos níveis de casca de soja sobre os consumos médios diários de matéria seca e de seus constituintes químicos estudados

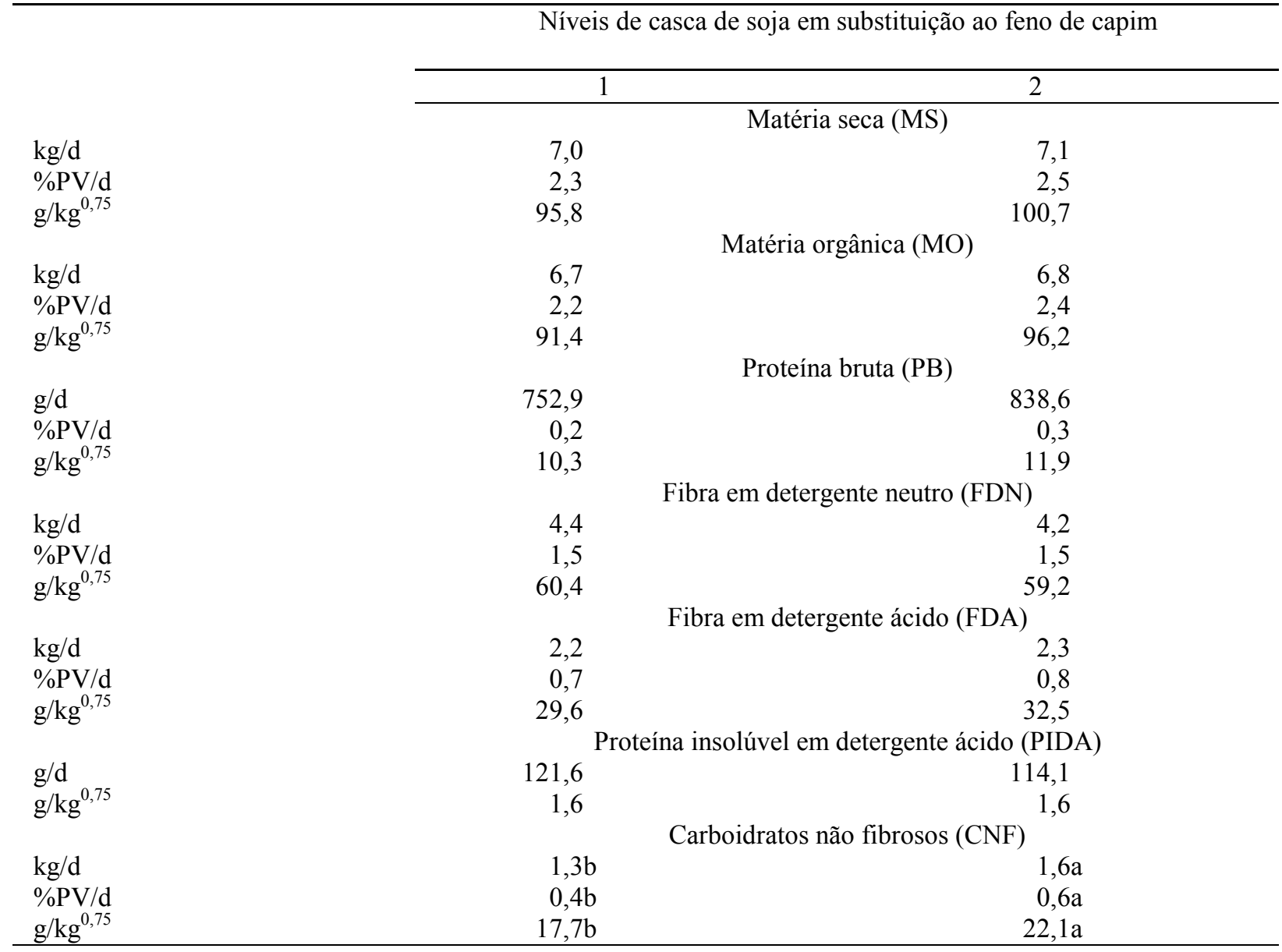

*Médias acompanhadas de letras diferentes na mesma linha diferem $(\mathrm{P}<0,05)$ pelo o teste de Tukey.

1- Rações completas com a casca de soja substituindo $30 \%$ do feno de capim coast-cross.

${ }^{2}$ - Rações completas com a casca de soja substituindo $70 \%$ do feno de capim coast-cross.

Não houve interações $(\mathrm{P}>0,05)$ entre fonte protéica e nível de casca de soja sobre os consumos de MS, MO, PB, FDN, FDA e de PIDA. Houve interações $(\mathrm{P}<0,05)$ entre fontes protéicas e níveis de substituições do feno de capim Coastcross por casca de soja para consumo de CNF em g/d, entretanto não foram detectadas para o consumo expresso em $\mathrm{g} / \mathrm{kg}^{0,75}$ (Tabela 5). Verifica-se, ainda, que dentro de fontes de proteína, apenas com o farelo de soja o nível de substituição de feno por casca de soja não apresentou efeito $(\mathrm{P}>0,05)$ sobre a ingestão de CNF. Estas diferenças, em parte, podem ser devidas à maior seletividade observada durante os períodos em que os animais receberam rações com $70 \%$ de casca de soja em substituição ao feno de capim Coastcross e o farelo de soja como a fonte de nitrogênio, nestas condições se observou maior sobra da fração concentrada. Neste sentido, quando as fontes suplementares de nitrogênio foram a amiréia e a FSSA os animais consumiram mais $(\mathrm{P}<0,05) \mathrm{CNF}$ quando as rações continham $70 \%$ de casca de soja em substituição ao feno de capim Coastcross do que aqueles alimentados com as mesmas fontes protéicas e com $30 \%$ de casca de soja em substituição ao mesmo feno.

O mesmo foi observado por Highfill et al. (1987), que relataram aumento no consumo das dietas com casca de soja, comparadas com farinha de gérmen de milho ou casca de soja mais farelo de trigo. 
Tabela 5. Efeitos dos níveis de casca de soja e das fontes protéicas sobre o consumo médio diário de carboidratos não fibrosos $(\mathrm{g} / \mathrm{d})$

\begin{tabular}{lccc}
\hline & \multicolumn{3}{c}{ Fontes } \\
\hline Níveis & Amiréia & Farinha de sub. abat. avícola & Farelo de soja \\
1 & $1536,9 \mathrm{~b}$ & $913,4 \mathrm{~b}$ & $1406,0 \mathrm{a}$ \\
2 & $1732,2 \mathrm{a}$ & $1581,1 \mathrm{a}$ & $1441,3 \mathrm{a}$ \\
\hline Teste $\mathrm{F}$ & & $10,15^{*}$ & \\
\hline
\end{tabular}

*Médias acompanhadas de letras diferentes na mesma coluna diferem $(\mathrm{P}<0,1015)$ pelo o teste $\mathrm{F}$.

1- Rações completas com a casca de soja substituindo $30 \%$ do feno de capim coast-cross.

${ }^{2}$ - Rações completas com a casca de soja substituindo $70 \%$ do feno de capim coast-cross.

Por outro lado, as ingestões de matéria seca em $\mathrm{g} / \mathrm{kg}^{0,75}$ determinadas no presente trabalho foram semelhantes àquelas relatadas por Queiroz et al. (1996), que encontraram ingestão de MS em animais Holandez x Nelore de 106,7 g/ $\mathrm{kg}^{0,75}$, alimentados com ração completa na proporção de 50:50\% de Volumoso/Concentrado. Foram, entretanto, inferiores aos resultados publicados por Araújo (1997), que relataram consumos médios de MS e MO em $\mathrm{g} / \mathrm{kg}^{0,75}$ de 129,9 e 118,8 , respectivamente, em trabalho conduzido com bovinos mestiços (7/8 Holandês $\mathrm{x}$ Zebu), alimentados com rações contendo diferentes percentagens de proteína degradável no rúmen (PDR).

Os resultados encontrados neste trabalho diferem dos publicados por Bernard e Mcneill (1991), que encontraram maior consumo de MS para rações contendo casca de soja do que para aquelas possuindo farelo de trigo, demonstrando que a casca de soja não reduziu a palatabilidade da ração. Estes autores, ainda, relataram maiores ingestões de FDA e FDN quando as vacas consumiram rações com casca de soja, o que não foi confirmado neste estudo.

Cecava et al. (1991) observaram aumentos na digestibilidade aparente total e ruminal e no intestino delgado da $\mathrm{MO}$, quando reduziram o nível de fibra da dieta de novilhos de 53,5 para $37,95 \%$, o que resultou também em depressão na digestibilidade aparente total e ruminal da FDN, cujos coeficientes decresceram de 71,7 para $67,5 \%$ e de 52,9 para $43,5 \%$, respectivamente.

A redução na digestibilidade ruminal da fibra pode ser compensada pela modificação no local de digestão, do rúmen para o ceco, que pode responder por até $30 \%$ da digestibilidade de componentes da fibra, como a celulose, em conseqüência da suplementação concentrada (SILVA; LEÃO, 1979).

\section{Conclusões}

A casca de soja pode substituir parcialmente a fração volumosa da ração de bovinos e a amiréia pode substituir totalmente o farelo de soja sem prejuízos na ingestão dos componentes nutricionais estudados.

\section{Referências}

ASSOCIATION OF OFFICIAL ANALYTICAL CHEMSTS. Official Methods of Analysis. 14 ${ }^{\text {th }} \mathrm{ed}$. Washington, 1998.

ARAÚJO, G. G. L. Consumo, digestibilidade, desempenho, composição corporal e exigências nutricionais de bezerros alimentados com dietas contendo diferentes níveis de volumoso. 1997. 104 p. Tese (Doutorado em Zootecnia) - Universidade Federal de Viçosa, Viçosa, 1997.

BERNARD, J. K.; MCNEIL, W. W. Effect of high fiber energy supplements on nutrient digestibility and milk production of lactating dairy cows. Journal of Dairy Science, Champaign, v. 74, n. 3, p. 991-9995, 1991.

CECAVA, M. J.; MERCHEN, N. R.; BERGER, L. L.; MACKIE, R. I.; FAHEY JR., G. C. Effects of dietary energy and protein source on nutrient digestion and ruminal nitrogen metabolism in steers. Journal of Animal Science, Champaign, v. 69, p. 2230-2243, 1991.

FORBES, J. M. Voluntary food intake and diet seletion in farm animals. Wallingford: CAB International, 1995. $532 \mathrm{p}$. 
HIGHFILL, B. D.; BOGGS, D. L.; AMOS, H. E.; CRICKMAN, J. G. Effects of high fiber energy supplements on fermentation characteriscs and in vivo and in situ digestibilities of low quality fescue hay. Journal of Animal Science, Champaign, v. 65, n. 1, p. 224-234, 1987.

MAC GREGOR, C. A.; OWEN, F. G.; MC GILL, L. D. Effect of increasing ration fiber with soybean mill run on digestibility and lactation performance. Journal of Dairy Science, Champaign, v. 59,p. 682-692, 1976.

MERTENS, D. R. Análise da fibra e sua utilização na avaliação e formulações de rações. In: REUNIÃO ANUAL DA SOCIEDADE BRASILEIRA DE ZOOTECNIA, 29., 1992, Lavras. Anais...Lavras, 1992. p.188-219.

MERTENS, D. R. Regulation of forage intake. In: FAHEY, G. C.; COLLINS, M.; MERTENS, D. R.; MOSER, L. E. (eds.) Forage quality, evalution and utilization. Nebraska: American Society of Agronomy, 1994. p. 450-493.

MERTENS, D. R., ELY, L. O. A dynamic model of fiber digestion and passage in the ruminant for evaluating forage quality. Journal of Animal Science, Champaign, v. 49, n. 4, p. 1085-1095,1979.

NATIONAL RESEARCH COUNCIL (NRC) - Nutrient requirements of beef cattle. 7. ed. Washington: National Academic Press, 1996. p. 242.
QUEIROZ, A. C.; SANCHEZ, N. R.; RESENDE, F. D. PEREIRA, J. C. Tamanho médio de partícula, módulo de finura e de uniformidade da digesta ao longo do trato gastrointestinal de ruminantes de diferentes grupos genéticos. Revista Brasileira de Zootecnia, Viçosa, v. 25, n. 1, p. 125-141, 1996.

ROSELER, D. K., FERGUSON, J. D., SNIFFEN, C. J. Dietary protein degradability effects on plasma and milk urea nitrogen and milk nonprotein nitrogen in holstein cows. Journal of Dairy Science, Champaign, v. 76, p. 525-534, 1993.

SAS. User's guide: statistics. 4. ed. Cary, North Carolina: SAS Institute, $1990.956 \mathrm{p}$.

SILVA, D. J., QUEIROZ, A. C. Análise de alimentos: métodos químicos e biológicos. 3. ed. Viçosa: Imprensa Universitária, $2002.235 \mathrm{p}$.

SILVA, J. F. C.; LEÃO, M. I. Fundamentos de nutrição de ruminantes.Piracicaba: Livroceres, 1979. 380 p.

VAN SOEST, P. J. Nutritional Ecology of the Ruminant. Ithaca: Cornell University Press, 1994. 476 p.

WALDO, D. R., JORGENSEN, N. S. Forage for high aniaml production: nutritional factors and effects of conservation. Journal of Dairy Science, Champaign, v. 64, p. 1207-1229, 1981. 